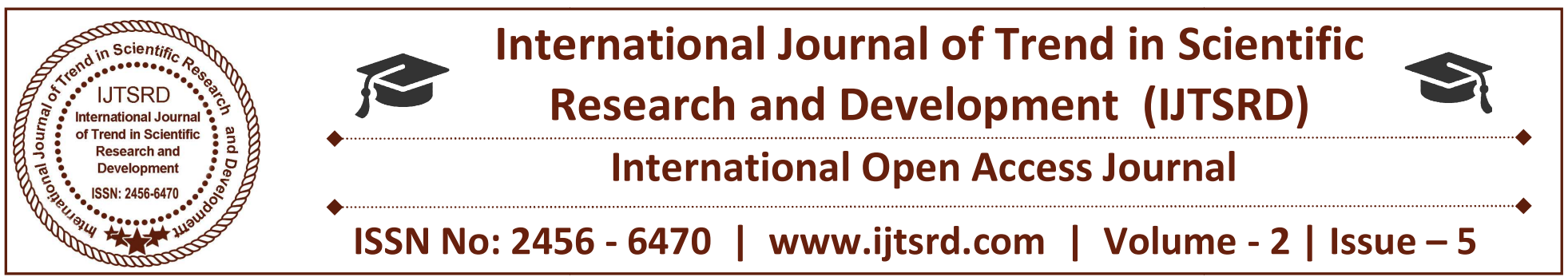

\title{
Impact of Pricing on Consumer Psychology
}

\author{
Madhushri Sharma \\ B.B.A., L.L.B (Hons), Indore Institute of Law, Affiliated By DAVV University, \\ Indore, Madhya Pradesh, India
}

\section{ABSTRACT}

The main purpose of this research is to measure the impact of pricing strategies on consumers' psychology and consumer buying behavior. This study theoretically examines the impact of pricing strategies used by companies on buying behavior of consumers. Main focus of researcher is to determine the effects of pricing strategies on consumer psychology. The study of consumer behavior is very challenging task where it is clear that if company wants to survive, it should be able to compete well. Researcher has took an latest example with case study on Reliance Jio info comm. Limited to study its market strategy and also to know its impact on consumer buying behavior because Reliance Jio has brought a vast change in market with its launched. There are so many strategies used by companies according to time, competition, and buying behavior of consumers. The study has used secondary data from research papers, monographs, theses, popular articles, and newspapers. Generally, consumers who are more price cognizant are more probable to select nine-ending prices. This study also covered the concept of penetration pricing strategy which is mostly used by marketers to grab the market and it seems very impactful on consumer's psychology.

Keywords: Psychological pricing; nine-ending prices; consumers' behavior; strategy; consumers' attitude; consumer psychology. Buying behavior, odd even strategy, bundle strategy, discount strategy, Consumer Psychology.

\section{Research methodology}

The data for this study have been taken from the secondary sources. Several journals, publications, working papers, books and published articles have been reviewed for the purpose. The whole of the study is based on the conceptual framework, which has been framed on the basis the factors found in the various psychological pricing-based literatures, and on their relationships. The main elements in the framework are consumers' socio-demographic factors, psychological patterns, attitude and buying behavior.

\section{INTRODUCTION}

Contemporary market of the world is highly stiff and competitive, and it is very challenging for the business organizations to sustain and grow in such a large business world. It is very important to recognize the consumers behavior also because consumers are the only source of profit for any business. The growing pressures of extremely competitive marketing environments make it crucial that organizations realize consumers and, in particular, consumers' decision-making process as they seek to gain competitive advantage. In the current economic system, the survival and growth of the organizations require accurate knowledge about consumers i.e., how they buy, why they buy and where they buy from as well as what they buy. These questions must be arising by company and they should try to find out its answer also. Hence, contemporary marketing thought stresses the need of business managers to know who their customers are and why they choose their products and services rather than those of competitors. The success of any particular organization depends upon the consumers and what they are actually willing to accept and pay for. There is a high competition between companies to get loyal customers and to sustain them. However, this is not an easy task for marketers, because several companies and brands compete simultaneously to sustain customers and get maximum profits. Studying consumer buying behavior has a vital role in understanding the factors 
that influence consumers' buying decisions. Customers are the primary focus of the marketing process and the benchmark to measure the success or failure of goods and services. Therefore, most of the companies study consumer behavior to increase the possibility of their success. Consumers take many decisions in their daily life and one of these is their buying decision. They decide to buy some products because of several reasons like need of the product, just want to try something new, recommendation of the product by someone or the products will be given as a gift. However, companies in different departments such as marketing and research and development study and analyze consumer behavior to set and introduce either new product/service or to develop an existing one. Basically, companies try to study and analyze the timing of purchasing, the buying mode, purchasing quantities, and the type of products or services. From all of these efforts that have been done, the main goal is to satisfy consumers and to make them loyal. This can be done by minimizing their costs and generate maximum revenue in smarter way. Because of globalization and booming in using electronic websites and social media, which enables consumers to do comparison between products and services with their prices at the same time, marketers need smart methods to attract consumers and to compete in this global worlds. Pricing is one of 4 P's of marketing mix which they are product, price, place and promotion. Pricing is the only clear factor that produces money and provides obvious signal of success or failure of products and services. Therefore, researcher in this study has chosen to closely highlight this factor. Many scholars and researchers had conducted studies on consumer buying behavior. The aim of this study is to evaluate and measure the impact of pricing strategies on consumers' psychology and their buying behavior. It highlights some strategies that are used by retailers to make the prices attractive to the consumers, penetration pricing, bundle pricing and discount pricing.

\section{TYPES OF PRICING STRATEGIES}

There are various factors which can affect the revenue of business and among all one of the most important factor is the pricing strategy utilized by the owners of business.

If company has made good price strategy then it will helpful for them to determine the growth and profit in near future. While setting prices, a business owner needs to consider a wide range of factors including production and distribution of cost, competitor offerings, positioning strategies and the business' target customer base.

While setting up pricing owner need to determine some aspects carefully because if price of a product is very then no one is going to purchase it on other hand if price is very then company cannot generate more profit as well as cannot cover production cost. Along with product, place and promotion, price can have a profound effect on the success of any business.

Here are some of the various strategies that businesses implement when setting prices on their products and services.

\section{Premium pricing}

In premium pricing strategy companies set costs higher than their competitors. Premium pricing is often most effective in the early days of a product's life cycle, and ideal for small businesses that sell unique goods.

Because some customers believes in quality and price tag so they need to perceive products as being worth the higher price tag, a business must work hard to create a value perception. Along with creating a highquality product, owners should ensure their marketing efforts, the product's packaging and the store's décor all combine to support the premium price.

\section{Penetration pricing}

This strategy aims to attract buyers by offering lower prices on goods and services. While many new companies use this technique to draw attention away from their competition, penetration pricing does tend to result in an initial loss of income for the business. Sometimes businesses which enter late in market they use this strategy to grab more consumer in short period of time.

Over time, however, the increase in awareness can drive profits and help small businesses to stand out from the crowd. In the long run, after sufficiently penetrating a market, companies often wind up raising their prices to better reflect the state of their position within the market.

\section{Economy Pricing}

Economy pricing strategy is used by a wide range of businesses including generic food suppliers and 
discount retailers where economy pricing aims to attract the most price-conscious of consumers. With this strategy, businesses minimize the costs associated with marketing and production in order to keep product prices down. As a result, customers can purchase the products they need without frills.

While economy pricing is incredibly effective for large companies like Wal-Mart and Target, the technique of economy pricing can be dangerous for small businesses because small businesses lack the sales volume of larger companies, they may struggle to generate a sufficient profit when prices are too low. Still, selectively tailoring discounts to most loyal customers can be a great way to guarantee their patronage for years to come.

\section{Price Skimming}

This strategy was designed to help businesses maximize sales on new products and services. It involves setting rates high during the introductory phase of product as they know that consumer has no option rather than buying their product however company can generate more profit. The company then lowers prices gradually as competitor goods appear on the market.

One of the best advantages of price skimming is that it allows businesses to maximize profits on early adopters before dropping prices to attract more pricesensitive consumers. Not only does price skimming help a small business recoup its development costs, but it also creates an illusion of quality and exclusivity when item is first introduced to the marketplace.

\section{Psychology Pricing}

Now days where economy is still limping back to full health price remains a major concern for consumers. Psychology pricing refers to techniques which is useful to encourage customers to respond on emotional levels rather than logical ones.

For example, setting the price of a watch at rupees 199 is proven to attract more consumers than setting it at rupees 200, even though the true difference here is quite small. One explanation for this trend is that consumers tend to put more attention on the first number on a price tag than the last. The goal of psychology pricing is to increase demand by creating an illusion of enhanced value for the consumer.

\section{Bundle Pricing}

In bundle pricing strategies, small businesses use to sell multiple products at a lower rate than consumers would face if they purchased each item individually. Not only is bundling goods an effective way of moving unsold items that are taking up space in facility of company, but it can also increase the value perception in the eyes of customer that company is giving something for free.

Bundle pricing is more effective for companies that sell complimentary products. For example, a restaurant can take advantage of bundle pricing by including dessert with every entrée sold on a particular day of the week. Small businesses should keep in mind that the profits they earn on the highervalue items must make up for the losses they take on the lower-value product.

\section{EFFECT OF PENETRATION PRICING STRATEGY}

Penetration pricing strategy is generally used by late comers in the market. This pricing is typically used when the market is saturated or there are already many variants of the same product present in the market. Penetration pricing gives an edge to the company because many customers are attracted on the basis of price or value for money and switch brands to adopt the brand offering low pricing on similar products. When there are same products available in market customer will like to pay for product which is lower in price than others so the study of this psychology of consumer brought the strategy of penetration pricing

Many times when you enter into supermarkets, you will see signs of "special introductory offers", the classical sign of penetration pricing strategy. There are dozens of soaps and shampoo's, all with different price points. Most of the times, you will find the price cheaper for those products, where there is little product differentiation and the demand is price elastic. Customers will not care about the brand when they can get the same product for the same quality at lower prices.

From the marketing objectives point of view, this strategy can lead to very interesting results if company has to look at the increase in market share and sales volumes due to use of penetrative pricing. When company lowers price, the sales volume increases and market share too may increase. By 
setting lower prices than competitors can also create barriers for the new entrees of companies into the market. For example, if there are 10 kinds of cheese, very similar in quality. According to budget of any particular customer than he will probably chose the cheapest one.. The low initial price has created an expectation of permanently low prices amongst consumers. Thus, if companies are not able to meet margins, and if they increase prices, the customer might switch again. The customer might leave their brand altogether, if another competitor is consistently offering the same quality of product at lower prices.

For more instance let's take an example of smart phones, when Apple came in the market with an astounding operating system and took away the market with skimming price. Later on, Samsung entered in the market with penetration pricing, taking away the smart phone market from Apple. After that, Apple remained at Skimming price due to its brand building efforts. But after that Micromax has took away market share from Samsung by using penetration strategy. And now Micromax is facing competition from other brands which are penetrating in the market and the cycle of penetrating strategies continue in the market. Thus, the customer who is price sensitive will keep switching to cheaper brands where he gets more value for the same money or same value for lesser money.

\section{Case study on reliance Jio Telecommunication} Company

Reliance Jio Info comm. Itd is a telecom company headed by MukeshAmbani. In the name of Reliance Jio, Ambani has entered the $4 \mathrm{G}$ market in late 2016 with a bang. Jio aims to be the largest telecommunications player within 3 years of launch. Entry strategy to achieve this is really strong as explained in the case. Unique selling prepositions and the impact in the market are explained in the case. Case also covers oligopoly market structure and how telecom industry in India is behaving after the launch of Jio. After effects in the market by consumers and service providers are explained in detail. There were so many challenges to attract the customers and retain them on the same platform are a question to discuss in this case. The Indian telecommunication sector which is the primarily voice calls driven, is now changing gears towards data driven. The voice calls, as it appears now, are going to be free. This shift in business model from voice centric to data centric can significantly impact the strategies of current players as there would be an increased pressure on profitability. Thanks to the entry of Reliance Jio. The rules of the game are re-written in the telecom industry. With its disruptive entry strategy, it has made most of the current strategies of competitors out-of-date. It perhaps created history in customer acquisition rate that it is hard to find a parallel example. This turbulence induced by the entry of Jio is impacting the industry in multiple ways. On one side, due to the availability of affordable data plans and smart-phones, the digitalized consumerism is bound to grow exponentially impacting almost every aspect of life. On the other hand, due to increased competition among the telecom companies, consumer acquisition and retention is going to be more expensive by further increasing the pressure on the profitability. These factors, along with high spectrum prices and friendly M\&A policies may prompt industry consolidation leading to fewer and stronger players left out in the fray. This case systematically analyses the impact of Jio's entry on Indian telecom industry and consumers.

\section{Reliance Jio:}

Reliance Jio Info communication Limited is the subsidiary company of Reliance industry which provides $4 \mathrm{G}$ network service. Jio is the only Vo-LTE (voice over LTE) provider in the country.

\section{Launch of Jio:}

Service was first Beta- Launched to its employees and partners in Dec 2015 and then later in September 2016 it was launched commercially for the public. Reliance Jio had already made a lot of buzz before the launch because of its amazing offers and it also showed in the results according to the reports in the very first month after its release Reliance Jio has acquired 16 million subscribers which is highest for any service provider in the world.

The number has increased to 50 million in 3 months and today Reliance Jio has more than 120 million users. Shahrukh Khan was appointed as the brand ambassador for the product.

Jio Apps: Jio has launched number of multimedia apps available on Google play store which requires Jio SIM card to function like JioTV, Jio Cinema, Jio Music and much more.

JioPhone: Jio has also launched a free of cost mobile phones with $4 \mathrm{G}$ connectivity named as Jio phone. 
You just have to pay security amount of 1500 rupees which can be withdrawn back after you return the phone after 3 Year to any Jio Store. You can pre-book your Jio phone from 24th August 2017.

4G Broadband: The Company has also started the 4G broadband service in September 2016.

Jio Wifi: Jio is also offering a portable wifi hotspot device through which you can access fast speed internet on your $2 \mathrm{G}$ and $3 \mathrm{G}$ devices by connecting your device to it. It comes at a very affordable price range of 2000-3000. So if you do not have $4 \mathrm{G}$ enabled phone you don't have to buy a new handset.

\section{Offers for Customer:}

Reliance Jio was launched with free unlimited calling and data usage for 3 months which was extended for another three months later as a special offer. This was one of the biggest reason for its popularity among the masses. After April 2017 customer has to pay for their calls and data usage there are many very reasonable price plans from which you can choose to use.

\section{Impact on Other Service Providers:}

Reliance Jio offers and data rates were so low that many people switched their existing network to Jio which cause a lot of unrest to the other operators due to which they have to make some drastic changes to remain in the competition. The merger of Idea with Vodafone and Airtel with Telenor are the result of that. Also, the data usage rates for other operators also came down drastically. It is safe to say that Jio has completely changed the way network operator used to charge the customers for the services.

\section{Impact on Digitalization of India:}

The Indian government was working on Digital India from last three year. The main aim of this scheme is to make all the government schemes and facilities online for which we need internet connectivity in low rates so that people can use these facilities. Reliance Jio has provided a big boost to this by providing fast pace internet at low rates. India is expecting to cross 500 million internet users this year which is a huge improvement over the last few years.

Low data usage rates made it possible not only in the urban area but also in rural areas. As per the reports in India, $48 \%$ of total internet users are from rural areas.

\section{Conclusion}

Through this research, it is concluded that there is a positive relationship between prices and consumer buying behavior (suitable prices make consumers more willing to purchase items). It also showed that there are number of pricing strategies in the market. The only thing is important is to know the consumer behavior accordingly. Company should more focus on quality and the price strategy they are using because this is the only technique which can lead to the success with growth of the business. In today's world of digitalization consumers are becoming more conscious about price and knowledge of product. There is no statistically significant difference between the responses of individuals "due to age, gender, marital status, qualification and monthly salary" about the pricing strategies except there is a statistically difference between the responses of individuals "due to gender" about the odd pricing strategy. Retailers and dealers are suggested to carefully study consumers buying behavior which is one of the most successful ways to know consumers' interests when making a purchase decision and to set suitable prices to their items as pricing has a direct impact on a company's revenue and consequently to its success. It is suggested that to segment consumer based on demographic characteristics and study carefully their needs and willingness to buy products or services. Moreover, here is an important factor that affects consumer buying behavior in positive way which is CSR(corporate social responsibility). If the company socially responsible and announce that the part of this payment of selected products will donate to non-profit organization or for event inside society that will encourage consumer to select the products of that particular company.

\section{REFERENCES}

1. https://quickbooks.intuit.com/r/pricing-strategy/6different-pricing-strategies-which-is-right-foryour-business/

2. https://quickbooks.intuit.com/r/pricing-strategy/6different-pricing-strategies-which-is-right-foryour-business/

3. http://www.acrwebsite.org/volumes/6321/volumes /v11/NA-11

4. https://www.researchgate.net/search/data? $\mathrm{q}=\mathrm{impa}$ ct $\% 2$ Bof $\% 2$ Bpricing $\% 2 B i n \% 2 B c o n s u m e r \% 2 B p s$ ychology

5. https://www.jstor.org 